\title{
High Resolution Computed Tomography (HRCT) Pattern characterization in Corona Virus Disease-2019 (COVID-19): A Meta-Analysis
}

Jatin Venugopal Kutnikar ${ }^{1 *}$, Syedha Fariheen Fathimah $\mathrm{M}^{1}$, Sneha Lalith ${ }^{2}$, Venkatraman Indiran ${ }^{3}$

\begin{abstract}
${ }^{1}$ MBBS, Sree Balaji Medical College and Hospital, Radiodiagnosis 7 Works Road Chromepet, Chennai, IN 600044, India ${ }^{2}$ MBBS, MD (Radiodiagnosis), Sree Balaji Medical College and Hospital, Radiodiagnosis 7 Works Road Chromepet, Chennai, IN 600044, India

${ }^{3}$ MBBS, MD (Radiodiagnosis), DNB (Radiodiagnosis), Sree Balaji Medical College and Hospital, Radiodiagnosis 7 Works Road Chromepet, Chennai, IN 600044, India
\end{abstract}

\section{Article History \\ Received: 07.10.2020 \\ Accepted: 23.10 .2020 \\ Published: 29.10 .2020}

Journal homepage:

$\underline{\text { https://www.easpublisher.com/easjms }}$

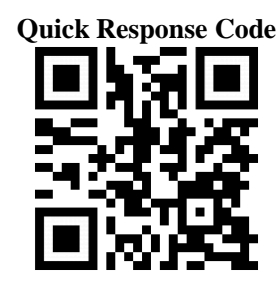

Abstract: Coronavirus disease-2019(COVID-19) pandemic has quickly become an infectious disease of worldwide concern and there exists gaps in the proper understanding of various patterns on HRCT imaging. This meta-analysis aims to summarise the most frequent HRCT patterns in COVID-19 from various published studies to aid the quick diagnosis. We aim to consolidate knowledge from original studies done on COVID-19 patients and characterise the imaging patterns on HRCT for quick diagnosis. This is a Meta-analysis on the various HRCT chest findings of COVID-19.Studies were procured from PubMed and Google Scholar database published between December 2019 and September 2020.The specific demographic and imaging patterns were analysed and pooled to form the metaanalysis using the random effects model and single-arm analysis. Total of 12 studies met the inclusion criteria. Total pooled data consisted of 2787 RT-PCR positive cases. The three CT patterns most characteristic included Ground Glass Opacities (52\%), Consolidation (40.4\%), Interlobular Septal Thickening (14\%). A combination of GGO and consolidation was most prevalent $(59 \%)$. Other patterns noted included Crazy Paving pattern, Air Bronchogram, Pleural thickening, Pleural effusion, Bronchiectasis and Tree in bud. Most cases were bilateral (79\%) and peripheral (77\%). Lower lobe involvement: bilateral (66\%), RLL (87\%), LLL (81\%). Upper lobe: Bilateral (61\%), RUL (65\%), LUL (69\%). Right Middle lobe (55\%). $25 \%$ had pan-lobar involvement. CT pattern recognition in potentially asymptomatic patients can be a diagnostic aid in early diagnosis of COVID-19. Ground glass opacities, consolidation and interlobar septal thickening in bilateral peripheral lungs was the most typical in COVID-19.

Keywords: COVID-19, HRCT-Chest patterns, Corona virus, CT-Thorax, Covid-19 Pneumonia.

Copyright (C) 2020 The Author(s): This is an open-access article distributed under the terms of the Creative Commons Attribution 4.0 International License (CC BY-NC 4.0) which permits unrestricted use, distribution, and reproduction in any medium for non-commercial use provided the original author and source are credited.

\section{INTRODUCTION}

Coronavirus disease 2019 (COVID-19), the now ongoing 2019-20 coronavirus pandemic [1, 2] is a viral disease caused by the severe acute respiratory syndrome coronavirus 2 (SARS-CoV-2) [3]. The first case was identified in the city of Wuhan; Hubei province of China in December 2019 and the outbreak was declared a Public Health Emergency of International Concern on 30 January 2020 by the World Health organization (WHO).

As of April 29th, 2020, there were 3,094,829 cases reported worldwide with $2,15,461$ deaths reported [4]. But over the span of 5 months, it has risen to $30,675,675$ reported cases of COVID-19 infection worldwide (as on 20th September, 2020) [8].

Most cases present with fever, cough, fatigue, shortness of breath and loss of smell [5]. More severe cases progress to viral pneumonia, multi-organ failure, or cytokine storm [6].

Incubation period ranges from 2 to 14 days. Hence early detection is of paramount importance. The standard method of diagnosis is by real-time reverse transcription polymerase chain reaction (RT-PCR) from a nasopharyngeal swab [7]. The role of CT imaging of the chest is rapid means of detecting cases of COVID19 although not recommended as a tool for screening. Patterns on CT chest to suggest COVID-19 is being extensively studied and here in this study we aim to consolidate the available data from all over the world in an attempt to find trends and frequency of each pattern.

\section{OBJECTIVES}

- To pool the existing research papers on the imaging findings of COVID-19 pandemic. 
- To compare the CT chest imaging patterns in COVID-19 infection with respect to the frequency in the different populations in the available studies.

- To represent the above data in tabular form and analyze and depict the results pictorially.

\section{MATERIALS AND METHODS \\ Retrieval of Studies}

An online search was made on PubMed and Google scholar using the keywords "COVID-19", "CTfindings in COVID-19", "novel corona virus", "COVID pneumonia" and "SARS- CoV2". This was in accordance to PRISMA (preferred reporting items for systematic reviews and meta-analyses) process.

The original articles were reviewed and additional supplementary studies were obtained under the list of references. The above papers were subjected to the inclusion and exclusion criteria for the purpose of this study. The papers included were as on $20^{\text {th }}$ September 2020.

\section{Inclusion Criteria}

1. Original articles of a cross sectional model and case series.

2. Papers that include CT chest findings of laboratory confirmed COVID-19 infection.

3. Papers that include the exact number of study subjects.

\section{Exclusion Criteria}

1. Case studies.

2. Lack of disclosure of exact number of study subjects.

3. Non-quantitative representation of imaging findings.

4. Full text was unavailable for the research paper.

5. Duplicated papers.

\section{Data Extraction}

The data obtained from the above process was consolidated into the following headings:

- First author, sample size of the study, place of study, age distribution (mean/median), sex distribution, CT protocol used, imaging findings and frequency of each feature.

- Imaging findings were further consolidated under Unilateral/Bilateral, Consolidation, Ground glass opacities (GGO), Interlobular septal thickening, Crazy Paving pattern, Air Bronchogram, Pleural thickening, Pleural effusion and Others.

- Distribution patterns were further evaluated under complete/peripheral/central; and lobes involved.

\section{Statistical Analysis}

All the numerical data was standardized by converting to a base unit/ measure appropriate for that variable. Measures of central tendency including mean and median with standard deviation, percentage data, discrete variables for frequency were recorded from the data set.

All the above data was recorded in Microsoft ( Excel for Mac version 2019. Stata and OpenMeta [Analyst] softwares were used to calculate the statistical data. The prevalence and 95\% Confidence interval was accepted for this study which used the binary randomeffect model. Statistical heterogeneity between studies was evaluated with Cochran's Q test and I2 statistic index. $\mathrm{P}$ value of $<0.10$ was taken as statistically significant for heterogeneity under the $\mathrm{Q}$ test and a value of $>50 \%$ was taken as cut off for I2 test for heterogeneity. Further analyses were done by grouping the data into smaller groups of age and sex, and other variables as determined during the analysis.

Pictorial representation was done using bar charts, histograms, pie charts and Forest plots.

\section{RESULTS}

\section{Literature Inclusion and Characteristics}

A total of 76 articles were retrieved from the online repositories. Of these, 23 studies contained original articles of a cross sectional model and case series and included CT chest findings of laboratory confirmed COVID-19 infection. After examining the full text of these 23 articles, we found 12 articles to include specific data on the CT patterns in order to compare and perform the meta-analysis. These 12 studies encompass 2787 laboratory confirmed COVID19 cases. The main characteristics of all the 12 articles is contained in Table 1 and 2.

The distribution of heterogeneity between studies was evaluated with Cochran's Q test and I2 statistic index. $\mathrm{P}$ value of $<0.05$ was obtained and thus was considered as statistically significant for heterogeneity under the Q test and a value of $99.9 \% \mathrm{I}^{2}$ test for heterogeneity was obtained, satisfying our initial requirements (Table-1).

\section{Demographical Characteristics}

The total study population encompassed 2787 positive cases of COVID-19 by RT-PCR. The mean age of patients in the included studies was $47.69 \pm 1.98$ years at $95 \%$ CI. Among the available data, 771 subjects were male and 803 were female (Figure-1).

Data for co-morbidities at the time of COVID19 was incomplete (Table-1; Figure 1, 2a, 2b).

\section{Imaging Findings}

Among the various characteristic patterns on CT imaging of the lung in 2787 COVID-19 patients, Ground Glass Opacities (GGOs) emerged as the most common finding (1451 subjects showed this pattern$52 \%$ of pooled subjects), followed by consolidation (1125 subjects showed this pattern- $40.4 \%$ of pooled 
subjects) and Interlobular septal thickening (400 subjects showed this pattern- $14 \%$ of pooled subjects). A combination of GGO and consolidation was the most prevalent (59\% of pooled subjects) (Table-2; Figure 3, $4,5)$.

Other patterns that were noteworthy include Crazy Paving pattern, Air Bronchogram, Pleural thickening, Pleural effusion, Bronchiectasis and Tree in bud. The incidence of each is as mentioned in Table-3. The data was incomplete for these patterns as most of the articles concentrated on the three predominant patterns (GGO, consolidation and Interlobular septal thickening).

Regarding the distribution of the lesions, most cases showed bilateral involvement (79\%) and peripheral distribution of lesions (77\%). Less than $10 \%$ of the lesions were noted in the hilar and peribronchovascular area.

Data for the lobe involvement was incomplete. From the available data set, Lower lobes were more frequently involved (RLL> LLL; $87 \%$ vs $81 \%$ ) and bilateral lower lobe involvement was $\sim 66 \%$. Upper lobe involvement was noted at LUL-69\%, RUL-65\% and bilateral upper lobes at $\sim 61 \%$. Right middle lobe was by far the least involved at $55 \%$. $21 \%$ of patients had involvement in all the lobes.

The Forest plots for GGOs and Consolidation is shown in Figure 6 and 7.

\section{DISCUSSION}

With 9,296,202 reported cases of COVID-19 infection worldwide as on 25th June, 2020 [8], this new emerging infection has caught the world by surprise with its worldwide spread since early January 2020. This is a test on the existing medical and healthcare infrastructure worldwide and is already proving the challenges in disaster preparedness [9]. As with every new emerging disease, the importance of epidemiology, diagnostic and treatment protocols along with development of preventive measures are of vital importance [10].

The diagnosis of COVID-19 is a matter of utmost interest as it encompasses the three pillarsclinical, laboratory and imaging. The clinical spectrum varies widely, ranging from asymptomatic to symptomatic (mild to severe) to ultimately being fatal [11].

Existing practices rely heavily on serological markers for the diagnosis of COVID-19. In this metaanalysis, we prove that $\mathrm{CT}$ imaging is a very relevant modality for early diagnosis of symptomatic and some asymptomatic primary contacts.

The symptomatic COVID-19 patient is an adult presenting with fever, cough and dyspnea with occasional myalgia. Of interest is the finding of GI symptoms like loss of appetite, diarrhea and vomiting at presentation [12].

It is believed that 4/5ths of cases are asymptomatic, as was first observed in China [13].

This study demonstrates that CT chest findings are very common in positive cases. Most frequent being GGO, followed by consolidation, interlobular septal thickening, pleural thickening, and air bronchograms. The involvement was mostly peripheral and bilateral with lower lobe predominance. Most of these patterns overlap with other viral pneumonia conditions such as common cold, influenza, MERS (Middle East Respiratory syndrome) and SARS (Severe Acute Respiratory Syndrome) [14]. Some RT-PCR negative patients show CT findings at presentation [15] and later become positive on RT-PCR on subsequent days. This set of population is vital in the broader sense of isolation and quarantine efforts. Studies indicate that the sensitivity of the sensitivity of the first reversetranscriptase PCR is $71 \%$ which is evidently lower than that of CT-Chest in COVID-19 [16].

One point of difference between other viral pneumonias and COVID-19 appears to be the more widespread bilateral involvement of lungs as noted in this study (79\%) versus the finding in MERS in which unilateral involvement is more common at presentation [17-20].

This meta-analysis has the merits of having a relatively large number of pooled cases (2787 COVID19 positive cases) that is spread over 3-4 months of this disease. The fact that these studies are based from various parts of China and the rest of the world make it more inclusive to the world population. The patterns mentioned in this study have been well defined and practiced by Radiologists the world over.

The lacunae of this study include the fact that asymptomatic cases were not included, which might have drastically altered the frequency of each pattern, as well as data deficits on the duration of the hospital stay, evolution of the disease and case fatalities. Details on comorbidities was not entirely available at the time of data collection. Lastly, the report was based on articles published by various groups of doctors, bringing in the inter-observer variations in the reporting of patterns and the fact that not all patterns were reported in every included study in this meta-analysis. 
Table-1: Demographics of reviewed studies

\begin{tabular}{|l|l|l|l|l|l|}
\hline Study & Country of Study & Sample size $(\mathbf{N})$ & Male & Female & Median age (in Years) \\
\hline Ai et al., [21] & China & 888 & 420 & 468 & 51 \\
\hline Bernheim et al., [22] & China & 121 & 61 & 60 & 45.3 \\
\hline Chen et al., [23] & China & 70 & 41 & 29 & 43 \\
\hline Duan et al., [24] & China & 238 & N/A & N/A & N/A \\
\hline Guan et al., [25] & China & 975 & N/A & N/A & 47 \\
\hline Jian Wu et al., [26] & China & 80 & 39 & 41 & 46.1 \\
\hline Pan et al., [27] & China & 63 & 33 & 30 & 44.9 \\
\hline Shi et al., [28] & China & 81 & 42 & 39 & 49.5 \\
\hline Song et al., [29] & China & 51 & 25 & 26 & 49 \\
\hline Wu et al., [30] & China & 80 & 42 & 38 & 44 \\
\hline XiXu et al., [31] & China & 90 & 39 & 51 & 50 \\
\hline Xu et al., $[32]$ & China & 50 & 29 & 21 & 54.8 \\
\hline TOTAL & & 2787 & 771 & 803 & 47.69 \\
\hline
\end{tabular}

Table-2: HRCT Patterns observed in the studies in the meta-analysis

\begin{tabular}{|c|c|c|c|c|c|c|c|}
\hline Study & $\mathbf{N}$ & Consolidation & $\begin{array}{lr}\text { Ground } & \text { Glass } \\
\text { Opacities (GGO) }\end{array}$ & $\begin{array}{l}\text { Interlobular } \\
\text { septal thickening }\end{array}$ & $\begin{array}{l}\text { Cochran's } \\
\text { Q }\end{array}$ & $\mathbf{p}$ & $\mathbf{I}^{2}$ \\
\hline Ai et al., [21] & 888 & 447 & 409 & 8 & 808.579 & $<0.05$ & 99.75 \\
\hline Bernheim et al., [22] & 121 & 52 & 91 & 14 & 115.506 & $<0.05$ & 98.26 \\
\hline Chen et al., [23] & 70 & 0 & 70 & 39 & 105.457 & $<0.05$ & 98.1 \\
\hline Duan et al., [24] & 238 & 29 & 45 & 6 & 59.128 & $<0.05$ & 96.61 \\
\hline Guan et al., [25] & 975 & 409 & 550 & 143 & 1197.069 & $<0.05$ & 99.83 \\
\hline Jian Wu et al., [26] & 80 & 55 & 0 & 0 & 110 & $<0.05$ & 98.18 \\
\hline Pan et al., [27] & 63 & 12 & 14 & 11 & 4.667 & 0.097 & 57.14 \\
\hline Shi et al., [28] & 81 & 17 & 53 & 28 & 56.722 & $<0.05$ & 96.47 \\
\hline Song et al., [29] & 51 & 28 & 39 & 38 & 34.696 & $<0.05$ & 94.23 \\
\hline Wu et al., [30] & 80 & 50 & 73 & 47 & 46.692 & $<0.05$ & 95.71 \\
\hline XiXu et al., [31] & 90 & 12 & 65 & 33 & 80.642 & $<0.05$ & 97.51 \\
\hline Xu et al., [32] & 50 & 15 & 30 & 33 & 31 & $<0.05$ & 93.54 \\
\hline TOTAL & 2787 & 1126 & 1439 & 400 & 2089.89 & $<0.05$ & 99.9 \\
\hline
\end{tabular}

Table 3: Other minor HRCT Patterns observed in the studies in the meta-analysis

\begin{tabular}{|c|c|c|c|c|c|c|c|}
\hline Study & $\mathbf{N}$ & $\begin{array}{l}\text { Crazy } \\
\text { Paving } \\
\text { pattern }\end{array}$ & $\begin{array}{l}\text { Air } \\
\text { Bronchogram }\end{array}$ & $\begin{array}{l}\text { Pleural } \\
\text { thickening }\end{array}$ & $\begin{array}{l}\text { Pleural } \\
\text { effusion }\end{array}$ & $\begin{array}{l}\text { Bronchi- } \\
\text { ectasis }\end{array}$ & tree in bud \\
\hline Ai et al., [21] & 888 & N/A & N/A & N/A & N/A & N/A & N/A \\
\hline Bernheim et al., [22] & 121 & 6 & N/A & N/A & 1 & 1 & N/A \\
\hline Chen et al., [23] & 70 & 38 & N/A & 34 & N/A & N/A & 9 \\
\hline Duan et al., [24] & 238 & N/A & N/A & N/A & N/A & N/A & N/A \\
\hline Guan et al., [25] & 975 & N/A & N/A & N/A & N/A & N/A & N/A \\
\hline Jian Wu et al., [26] & 80 & N/A & N/A & N/A & N/A & N/A & N/A \\
\hline Pan et al., [27] & 63 & N/A & N/A & N/A & N/A & N/A & N/A \\
\hline Shi et al., [28] & 81 & N/A & N/A & 26 & 4 & 9 & N/A \\
\hline Song et al., [29] & 51 & N/A & 41 & N/A & 4 & N/A & N/A \\
\hline Wu et al., [30] & 80 & 23 & N/A & N/A & 5 & N/A & N/A \\
\hline XiXu et al., [31] & 90 & 11 & 7 & 50 & 4 & N/A & N/A \\
\hline $\mathrm{Xu}$ et al., [32] & 50 & N/A & 22 & N/A & 4 & N/A & N/A \\
\hline TOTAL & 2787 & 78 & 70 & 110 & 22 & 10 & 9 \\
\hline
\end{tabular}




\section{AGE DISTRIBUTION}

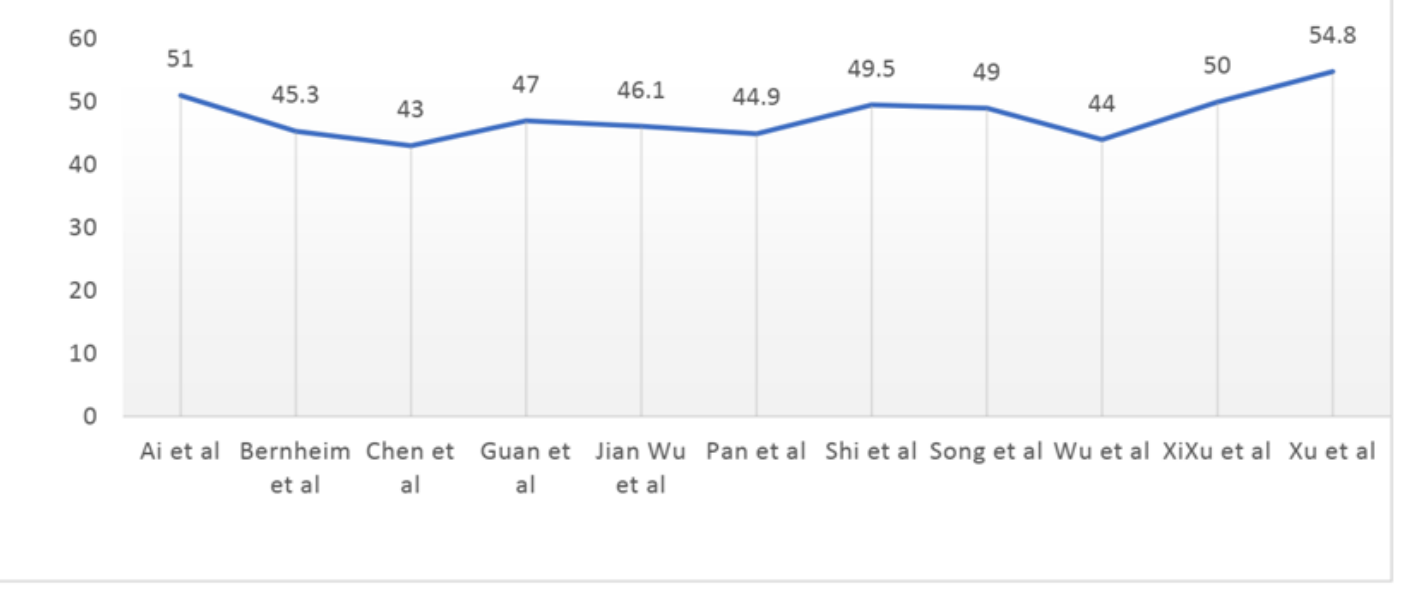

Fig-1: Age distribution of subjects in the meta-analysis

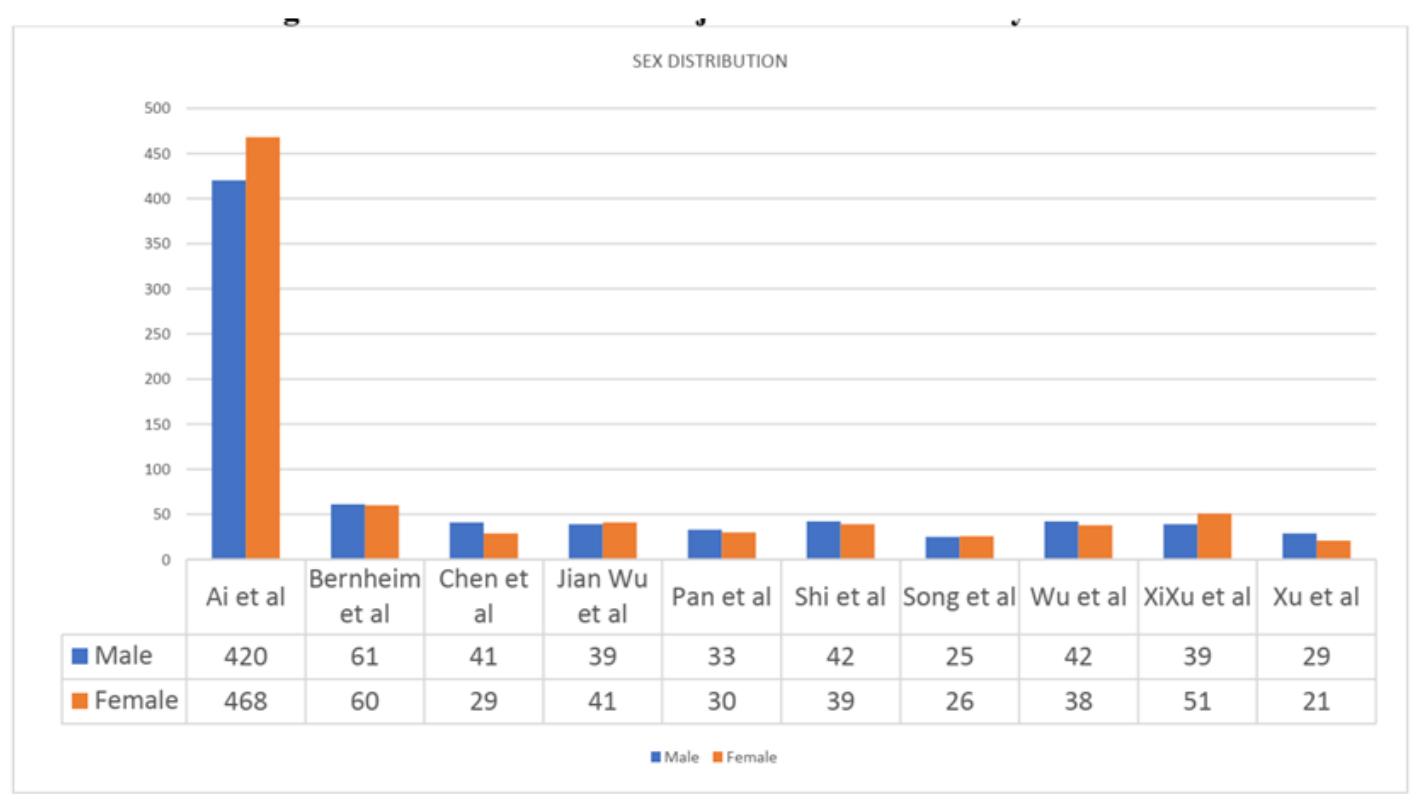

Fig-2a: Sex distribution of subjects in the meta-analysis

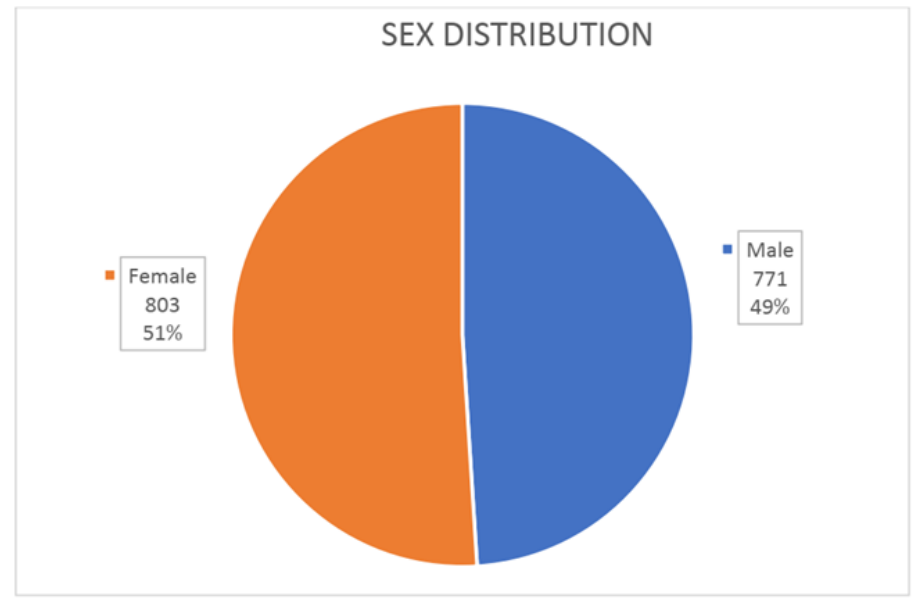

Fig-2b: Pie Chart of Sex distribution 


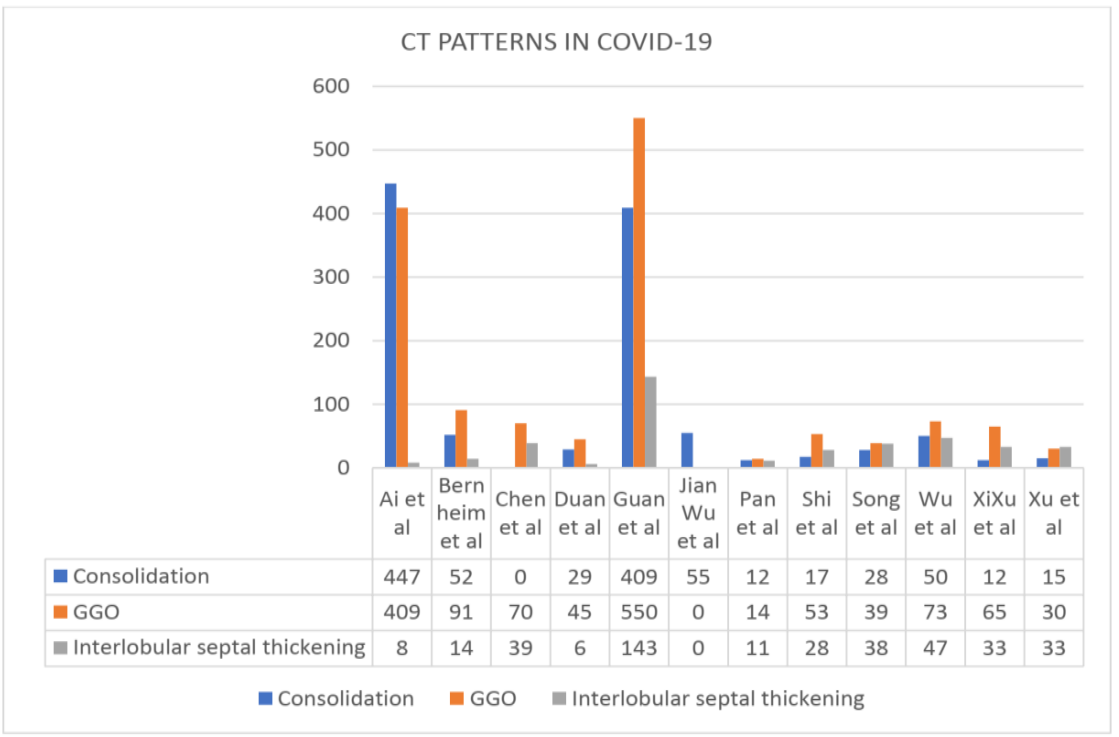

Fig-3: CT-Chest patterns in COVID-19

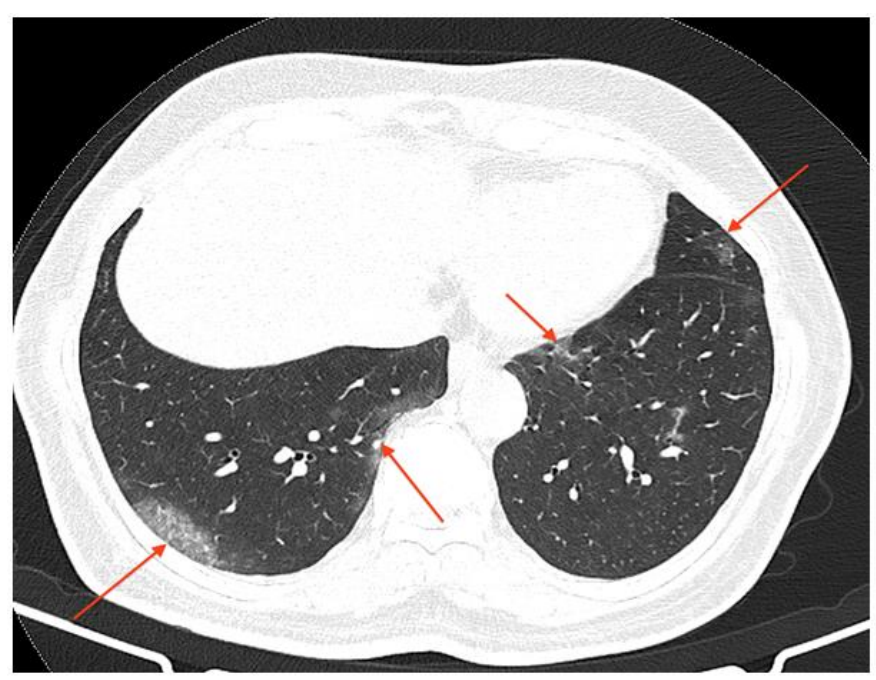

Fig-4: HRCT Chest of a 64-year COVID-19 positive male patient. Arrows represent areas of peripherally distributed Ground Glass Opacities (GGOs) in the basal segments of both lung fields, and lateral lingular segment of the left upper lobe. GGOs are the most common CT pattern in COVID-19

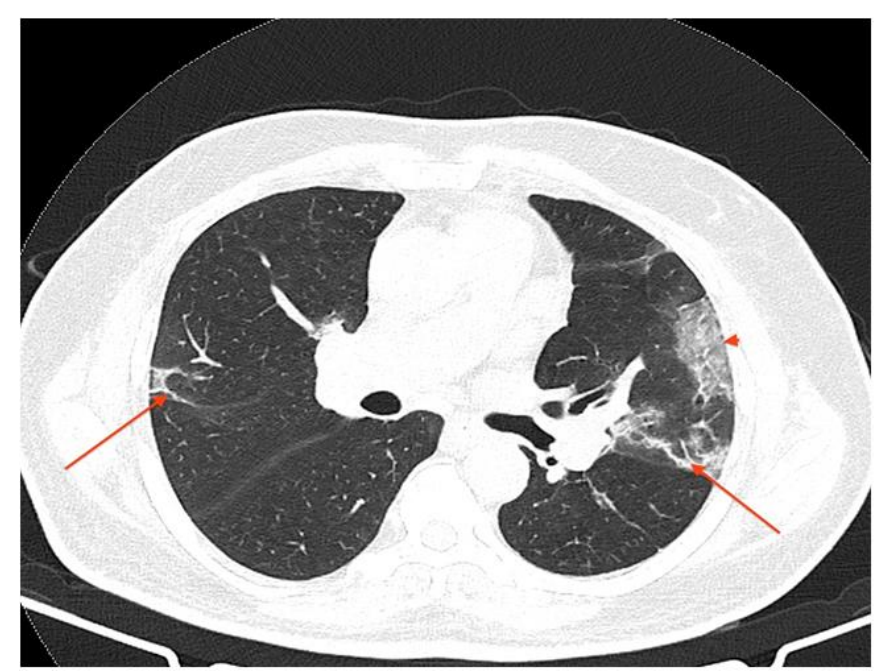

Fig-5: HRCT Chest of the same 64-year COVID-19 positive male patient. Higher sections show Interlobular Septal Thickening pattern (arrows) involving the lateral segment of right upper lobe and posterior segment of left upper lobe. Arrow head represents a combination of consolidation and Ground Opacity in the posterior segment of left upper lobe 


\section{FOREST PLOT OF STUDIES FOR GGO PATTERN}

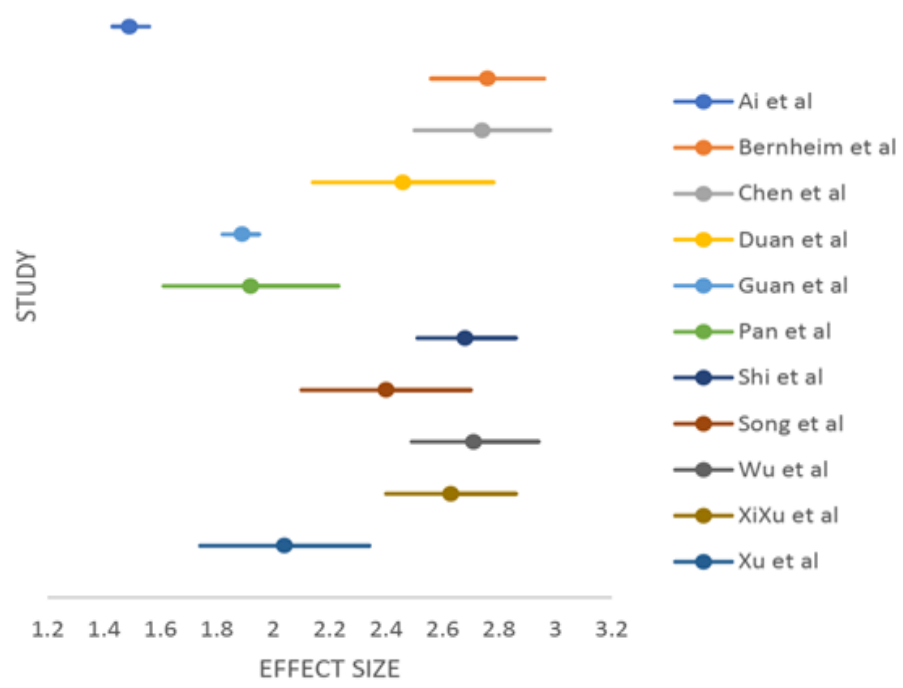

Fig-6: Forest Plot with data set of studies For GGO Pattern

\begin{tabular}{|l|l|l|l|l|}
\hline Study & Consolidation & ES & 95\% CI LOWER & 95\% CI UPPER \\
\hline Ai et al., & 409 & 1.49 & 1.43 & 1.56 \\
\hline Bernheim et al., & 91 & 2.76 & 2.56 & 2.96 \\
\hline Chen et al., & 70 & 2.74 & 2.5 & 2.98 \\
\hline Duan et al., & 45 & 2.46 & 2.14 & 2.78 \\
\hline Guan et al., & 916 & 1.89 & 1.82 & 1.95 \\
\hline Pan et al., & 14 & 1.92 & 1.61 & 2.23 \\
\hline Shi et al., & 53 & 2.685 & 2.51 & 2.86 \\
\hline Song et al., & 51 & 2.4 & 2.1 & 2.7 \\
\hline Wu et al., & 73 & 2.71 & 2.49 & 2.94 \\
\hline XiXu et al., & 65 & 2.63 & 2.4 & 2.86 \\
\hline Xu et al., & 30 & 2.04 & 1.74 & 2.34 \\
\hline
\end{tabular}

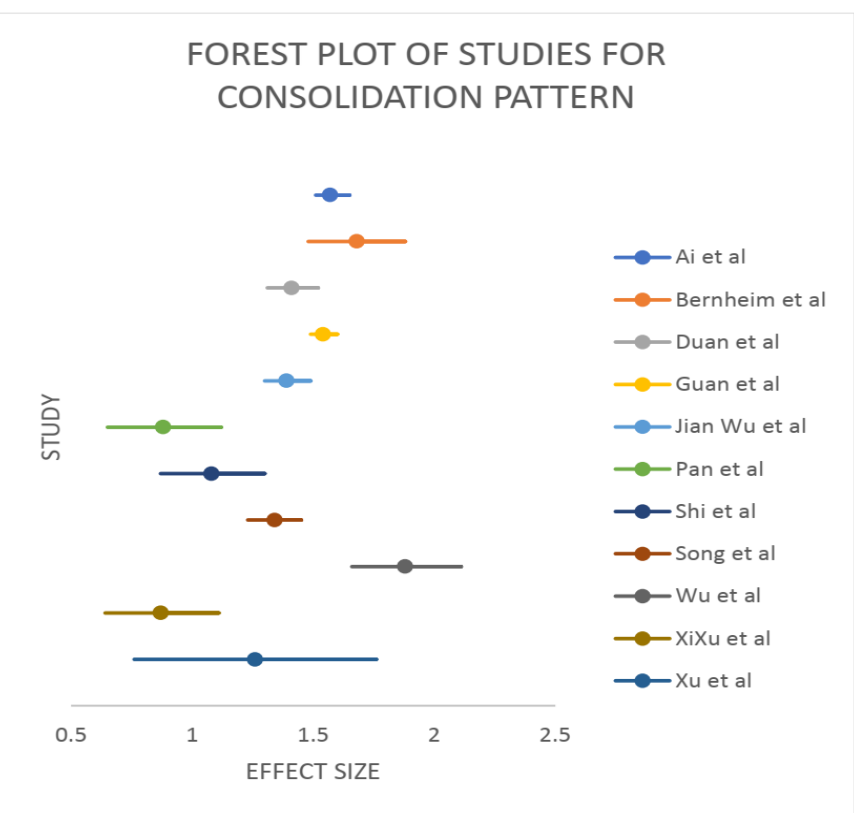

Fig-7: Forest Plot with data set of studies For Consolidation Pattern 


\begin{tabular}{|l|l|l|l|l|}
\hline Study & Consolidation & ES & 95\% CI LOWER & 95\% CI UPPER \\
\hline Ai et al., & 447 & 1.575 & 1.51 & 1.64 \\
\hline Bernheim et al., & 52 & 1.68 & 1.48 & 1.88 \\
\hline Duan et al., & 29 & 1.415 & 1.31 & 1.52 \\
\hline Guan et al., & 409 & 1.545 & 1.49 & 1.6 \\
\hline Jian Wu et al., & 55 & 1.395 & 1.3 & 1.49 \\
\hline Pan et al., & 12 & 0.885 & 0.65 & 1.12 \\
\hline Shi et al., & 17 & 1.085 & 0.87 & 1.3 \\
\hline Song et al., & 28 & 1.34 & 1.23 & 1.45 \\
\hline Wu et al., & 50 & 1.885 & 1.66 & 2.11 \\
\hline XiXu et al., & 12 & 0.875 & 0.64 & 1.11 \\
\hline Xu et al., & 15 & 1.26 & 0.76 & 1.76 \\
\hline
\end{tabular}

\section{REFERENCES}

1. Hui, D. S., Azhar, E. I., Madani, T. A., Ntoumi, F., Kock, R., Dar, O., ... \& Zumla, A. (2020). The continuing 2019-nCoV epidemic threat of novel coronaviruses to global health-The latest 2019 novel coronavirus outbreak in Wuhan, China. International Journal of Infectious Diseases, 91, 264-266.

2. "WHO Director-General's opening remarks at the media briefing on COVID-19". World Health Organization (WHO) (Press release). 11 March 2020. Archived from the original on 11 March 2020. Retrieved 12 March 2020.

3. "Coronavirus disease 2019 (COVID-19) Symptoms and causes". Mayo Clinic. Retrieved 14 April 2020.

4. "COVID-19 Dashboard by the Center for Systems Science and Engineering (CSSE) at Johns Hopkins University (JHU)". ArcGIS. Johns Hopkins University. Retrieved 28 April 2020.

5. "Symptoms of Coronavirus". U.S. Centers for Disease Control and Prevention (CDC). 20 March 2020. Archived from the original on 30 January 2020.

6. Mehta, Puja; McAuley, Daniel F.; Brown, Michael; Sanchez, Emilie; Tattersall, Rachel S.; Manson, Jessica J. (28 March 2020). "COVID-19: consider cytokine storm syndromes and immunosuppression". The Lancet. 395 (10229): 1033-1034. doi:10.1016/S0140-6736(20)30628-0. ISSN 0140-6736. PMID 32192578.

7. "Interim Guidelines for Collecting, Handling, and Testing Clinical Specimens from Persons for Coronavirus Disease 2019 (COVID-19)". Centers for Disease Control and Prevention (CDC). 11 February 2020. Archived from the original on 4 March 2020. Retrieved 26 March 2020.

8. World Health Organization. Novel coronavirus (2019-nCoV) - situation report - 157 -25 June $2020 . \quad$ https://www.who.int/docs/defaultsource/coronaviruse/situation-reports/20200625covid-19-sitrep-157.pdf?sfvrsn=423f4a82_2

9. Wu, F., Zhao, S., Yu, B., Chen, Y. M., Wang, W., Song, Z. G., ... \& Yuan, M. L. (2020). A new coronavirus associated with human respiratory disease in China. Nature, 579(7798), 265-269.
10. Paules, C. I., Marston, H. D., \& Fauci, A. S. (2020). Coronavirus infections - more than just the common cold. Jama, 323(8), 707-708.

11. Lipsitch, M., Swerdlow, D. L., \& Finelli, L. (2020). Defining the epidemiology of Covid-19-studies needed. New England journal of medicine, 382(13), 1194-1196.

12. Pan, L., Mu, M., Yang, P., Sun, Y., Wang, R., Yan, J., ... \& Jin, Y. (2020). Clinical characteristics of COVID-19 patients with digestive symptoms in Hubei, China: a descriptive, cross-sectional, multicenter study. The American journal of gastroenterology, 115.

13. Day, M. (2020). Covid-19: four fifths of cases are asymptomatic, China figures indicate.

14. De Wit, E., Van Doremalen, N., Falzarano, D., \& Munster, V. J. (2016). SARS and MERS: recent insights into emerging coronaviruses. Nature Reviews Microbiology, 14(8), 523.

15. Xie, X., Zhong, Z., Zhao, W., Zheng, C., Wang, F., \& Liu, J. (2020). Chest CT for typical 2019-nCoV pneumonia: relationship to negative RT-PCR testing. Radiology, 200343.

16. Fang, Y., Zhang, H., Xie, J., Lin, M., Ying, L., Pang, P., \& Ji, W. (2020). Sensitivity of chest CT for COVID-19: comparison to RT-PCR. Radiology, 200432.

17. De Wit, E., Van Doremalen, N., Falzarano, D., \& Munster, V. J. (2016). SARS and MERS: recent insights into emerging coronaviruses. Nature Reviews Microbiology, 14(8), 523-534.

18. Hui, D. S., \& Zumla, A. (2019). Severe acute respiratory syndrome: historical, epidemiologic, and clinical features. Infectious Disease Clinics, 33(4), 869-889.

19. Zu, Z. Y., Jiang, M. D., Xu, P. P., Chen, W., Ni, Q. Q., Lu, G. M., \& Zhang, L. J. (2020). Coronavirus disease 2019 (COVID-19): a perspective from China. Radiology, 200490.

20. Kooraki, S., Hosseiny, M., Myers, L., \& Gholamrezanezhad, A. (2020). Coronavirus (COVID-19) outbreak: what the department of radiology should know. Journal of the American college of radiology. 17: 447-51.

21. Ai, T., Yang, Z., Hou, H., Zhan, C., Chen, C., Lv, W., ... \& Xia, L. (2020). Correlation of chest CT and RT-PCR testing in coronavirus disease 2019 
(COVID-19) in China: a report of 1014 cases. Radiology, 200642.

22. Bernheim, A., Mei, X., Huang, M., Yang, Y., Fayad, Z. A., Zhang, N., ... \& Li, S. (2020). Chest CT findings in coronavirus disease-19 (COVID19): relationship to duration of infection. Radiology, 200463.

23. Chen X, Tang Y, Mo Y, Li S, Lin D, Yang Z, Yang Z, Sun H, Qiu J, Liao Y, Xiao J. A diagnostic model for coronavirus disease 2019 (COVID-19) based on radiological semantic and clinical features: a multi-center study. European radiology. 2020 Apr 16:1.

24. Duan, Y. N., Zhu, Y. Q., Tang, L. L., \& Qin, J. (2020). CT features of novel coronavirus pneumonia (COVID-19) in children. European Radiology, 1-7.

25. Guan, W. J., Ni, Z. Y., Hu, Y., Liang, W. H., Ou, C. Q., He, J. X., .. \& Du, B. (2020). Clinical characteristics of coronavirus disease 2019 in China. New England journal of medicine, 382(18), 1708-1720.

26. Wu, J., Liu, J., Zhao, X., Liu, C., Wang, W., Wang, D., ... \& Cao, H. (2020). Clinical characteristics of imported cases of COVID-19 in Jiangsu province: a multicenter descriptive study. Clin Infect Dis, 10 .

27. Pan, Y., Guan, H., Zhou, S., Wang, Y., Li, Q., Zhu, T., ... \& Xia, L. (2020). Initial CT findings and temporal changes in patients with the novel coronavirus pneumonia (2019-nCoV): a study of 63 patients in Wuhan, China. European radiology, $1-4$.

28. Shi, H., Han, X., Jiang, N., Cao, Y., Alwalid, O., Gu, J., ... \& Zheng, C. (2020). Radiological findings from 81 patients with COVID-19 pneumonia in Wuhan, China: a descriptive study. The Lancet Infectious Diseases.

29. Song, F., Shi, N., Shan, F., Zhang, Z., Shen, J., Lu, H., ... \& Shi, Y. (2020). Emerging 2019 novel coronavirus (2019-nCoV) pneumonia. Radiology, 295(1), 210-217.

30. Wu, J., Wu, X., Zeng, W., Guo, D., Fang, Z., Chen, L., .. \& Li, C. (2020). Chest CT findings in patients with coronavirus disease 2019 and its relationship with clinical features. Investigative radiology, 55(5), 257.

31. Xu, X., Yu, C., Qu, J., Zhang, L., Jiang, S., Huang, D., ... \& Jiang, R. (2020). Imaging and clinical features of patients with 2019 novel coronavirus SARS-CoV-2. European journal of nuclear medicine and molecular imaging, 1-6.

32. Xu, Y. H., Dong, J. H., An, W. M., Lv, X. Y., Yin, X. P., Zhang, J. Z., ... \& Gao, B. L. (2020). Clinical and computed tomographic imaging features of novel coronavirus pneumonia caused by SARSCoV-2. Journal of Infection. 